\title{
Date of First Ever Onset of Angina Pectoris
}

National Cancer Institute

\section{Source}

National Cancer Institute. Date of First Ever Onset of Angina Pectoris. NCI Thesaurus.

Code C91339.

The date of the beginning of the first ever occurrence of the symptom complex of angina pectoris. 